\title{
Pengaruh Suhu Penyimpanan Elektroda Low Hydrogen E7016 terhadap Hasil Uji Tekuk Sambungan Las Pelat Baja Karbon SS400
}

\author{
Miftahrur Bin Afan*, Purwantono, Mulianti, Bulkia Rahim \\ Jurusan Teknik Mesin, Fakultas Teknik, Universitas Negeri Padang \\ Jl. Prof. Dr. Hamka, Kampus UNP Air Tawar, Padang 25131 \\ *E-mail: miftahrur@gmail.com
}

\begin{abstract}
Abstrak
Pengelasan merupakan proses penyambungan logam dengan menggunakan bahan tambah berupa elektroda. Sebelum melakukan pengelasan salah satu faktor penting yaitu perlakuan elektroda. Hal tersebut penting dilakukan terutama pada perlakuan penyimpanan elektroda tipe basic low hydrogen (E7016). Penelitian sebelumnya menunjukkan bahwa pemanasan elektroda dapat menghindari retak sambungan las pada uji face bend. Tujuan penelitian ini yaitu untuk mengungkapkan pengaruh perlakuan suhu penyimpanan elektroda terhadap uji tekuk sambungan las. Metode dalam penelitian ini menggunakan penelitian eksperimen, dimana penelitian dilakukan dengan memberi perlakuan pada suhu penyimpanan elektroda. Elektroda diberi perlakuan suhu penyimpanan dengan variasi $40^{\circ} \mathrm{C}, 80^{\circ} \mathrm{C}$, dan $120^{\circ} \mathrm{C}$ selama 30 menit. Elektroda yang digunakan yaitu jenis low hydrogen (E7016) dan material sampel menggunakan pelat SS400. Sambungan las menggunakan kampuh V tunggal dan pengelasan sampel menggunakan proses shield metal arc welding. Pengujian tekuk spesimen dilakukan sesuai standar American Welding Society D1.1. Hasil penelitian menunjukkan bahwa semakin tinggi suhu penyimpanan akan menghasilkan daya tahan retak yang baik pada uji face bend dibandingkan dengan hasil pengujian root bend.
\end{abstract}

Received: 15 -03-2020; Accepted: 16-04-2020; Published online: 23-04-2020

Kata kunci: Baja SS400; E7016; Shield metal arc welding; Suhu penyimpanan; Uji tekuk

\begin{abstract}
Welding is a process of joining metals use filler metal electrodes. Before welding, one important factor is the electrode treatment. This is especially important in the treatment electrode storage type of basic low hydrogen (E7016). Previous studies have shown that electrode heating can avoid cracking of the welded joints on the face bend test. The purpose of this study is to reveal the effect of the electrode storage temperature treatment on the bend test of the welded joint. The method in this study uses experimental research, where research is done by giving treatment to the electrode storage temperature. The electrodes are given storage temperature treatment with variations of $40^{\circ} \mathrm{C}, 80^{\circ} \mathrm{C}$ and $120^{\circ} \mathrm{C}$ for 30 minutes. The electrodes used are low hydrogen (E7016) and sample material using SS400 plates. Welding joints use a single V-groove and welded sample using the shield metal arc welding process. The bend test is done according to American Welding Society standard D1.1. The results showed that the higher storage temperature will produce good crack resistance in face bend test compared to the results of root bend testing.
\end{abstract}

Keywords: Bend test; E7016; Shield metal arc welding; SS400 steel; Storage temperature

\section{Pendahuluan}

Shield metal arc welding (SMAW) merupakan proses menyambung logam dengan mencairkannya melalui pemanasan menggunakan busur elektroda [1]. Bahan tambah dalam proses las ini menggunakan elektroda habis pakai yang dilapisi oleh fluks untuk melindungi cairan las dari proses oksidasi. Saat proses penyambungan logam dilakukan bahan tambah tersebut akan mencair bersamaan dengan logam yang disambung dan cairan akan membeku sehingga menghasilkan sambungan las. Proses pengelasan ini banyak digunakan di industri pemeliharaan dan perbaikan, kontruksi baja struktur serta industri fabrikasi [2]. Keuntungan dari las ini yaitu peralatan murah, serbaguna untuk melakukan pengelasan pada berbagai variasi desain sambungan las, jenis logam, ketebalan logam, posisi las, dan peralatan mudah untuk dipindahkan dari satu tempat ke tempat lain [3].

Sebelum melakukan pengelasan salah satu faktor penting yaitu perlakuan elektroda. Bahan pelindung elektroda jenis low hydrogen (E7016) memiliki batas kadar maksimum kelembapan yaitu 0,6\% [4]. Penyimpanan elektroda E7016 di lapangan umumnya setelah selesai digunakan disimpan kembali pada kemasannya sehingga tidak cukup terlindungi dari 
udara sekitarnya dan menyebabkan bahan pelindung menjadi lembap. Akibat kondisi pelindung elektroda yang lembap dapat menyebabkan terjadinya cacat pada hasil las seperti spatters dan porosity [5]. Selain itu, keberadaan cacat las pada sambungan dapat mengurangi kekuatan dan tingkat mutu sambungan las. Secara visual kelembapan bahan pelindung elektroda dapat dilihat pada kondisi bahan pelindungnya, umumnya elektroda yang lembap cenderung memiliki warna gelap. Penyimpanan elektroda tipe ini harus pada tempat yang kering dan terhindar dari lingkungan yang lembap. Untuk penyimpanan elektroda jenis low hydrogen (E7016) setelah dibuka dari kemasan pabrik dapat disimpan pada suhu $30^{\circ} \mathrm{C}-140^{\circ} \mathrm{C}$ [6].

Penelitian tentang suhu penyimpanan atau pemanasan elektroda telah dilakukan oleh beberapa peneliti, yaitu Habibi [7] melakukan penelitian dengan tujuan mengetahui pengaruh perlakuan pemanasan elektroda terhadap uji tarik dan struktur mikro, hasilnya menunjukkan bahwa kualitas sambungan las dapat diperoleh dengan hasil yang baik dengan pemanasan suhu yang tinggi. Gumono [8] telah melakukan studi perbandingan suhu penyimpanan elektroda untuk mengetahui kekerasan sambungan las, hasilnya menunjukkan bahwa terdapat perbedaan nilai kekerasan dan kekerasan maksimum didapat pada suhu $75^{\circ}$ C. Wibowo [9] dalam penelitiannya melakukan pengujian tarik, face bend, dan kekerasan untuk mengetahui pengaruh perlakuan pemanasan dan tanpa pemanasan pada elektroda. Pada hasil pengujian tersebut perlakuan suhu $150^{\circ} \mathrm{C}$ dapat menghindari retak dan menghasilkan kekuatan sambungan las paling optimal.

Hasil dari beberapa penelitian sebelumnya dapat digunakan untuk mengetahui efek suhu pemanasan terhadap sifat sambungan las. Walaupun demikian, hasil penelitian belum dapat mengidentifikasi cacat sambungan las dengan baik. Selain itu, diantara penelitian sebelumnya tidak mengkaji pengaruh suhu penyimpanan elektroda terhadap pengujian root bend. Oleh karena itu, perlu adanya studi pengujian tekuk sambungan las lebih lanjut terutama dalam mengidentifikasi retak las. Dalam penelitian ini bertujuan untuk mengungkapkan lebih lanjut pengaruh suhu penyimpanan elektroda terhadap hasil uji tekuk sambungan las kampuh V tunggal pada material pelat SS400.

\section{Material dan metodologi}

\subsection{Material}

Material yang digunakan dalam penelitian ini yaitu pelat baja karbon rendah JIS G3101 Gr. SS400 dengan ketebalan $8 \mathrm{~mm}$. Material tersebut memiliki kekuatan tarik 428 Mpa dan kekuatan luluh 310 Mpa. Komposisi material ini dapat dilihat pada Tabel 1. Ukuran material yang digunakan yaitu 200 mm x 100 mm x 8 mm. Elektroda yang digunakan adalah jenis low hydrogen klasifikasi (AWS E7016) dengan diameter 2,6 mm dan 3,2 mm, komposisi kimia elektroda ini dapat dilihat pada Tabel 2. Elektroda tersebut dipilih berdasarkan material yang akan digunakan sebagai sampel. Mutu dari hasil pengelasan sangat dipengaruhi oleh pemilihan elektroda sebagai logam pengisi dalam proses pengelasan logam [10]. Material SS400 yang digunakan dalam penelitian ini merupakan baja karbon rendah yang umum digunakan untuk material kontruksi dan memiliki kemampuan las (weldability) yang baik. Proses pengelasan baja SS400 dalam penelitian ini menggunakan elektroda E7016, hal ini sesuai dengan Jeffus [11] yang menyatakan bahwa elektroda E7016 dapat digunakan untuk mengelas material kontruksi.

Tabel 1. Komposisi Kimia Material SS400

\begin{tabular}{lcccccccc}
\hline Element & C & Si & Mn & P & S & Cr & Ni & N \\
\hline \% Of Wt & 0,14 & 0,13 & 0,69 & 0,009 & 0,005 & 0,01 & 0,01 & $<0,008$ \\
\hline
\end{tabular}


Tabel 2. Komposisi Kimia Elektroda E7016 [12]

\begin{tabular}{ccccccccccc}
\hline Element & C & Si & Mn & P & S & Ni & Cr & Mo & V \\
\hline \% Of Wt & 0,08 & 0,60 & 0,94 & 0,011 & 0,006 & 0,01 & 0,02 & $<0,01$ & 0,01 \\
\hline
\end{tabular}

\subsection{Desain Sambungan Las}

Desain sambungan las menggunakan kampuh V tunggal dengan sudut kampuh $60^{\circ}$, root face 2 mm, dan root gap 2 mm yang dipersiapkan dengan mesin gerinda, dapat dilihat desain sambungan las kampuh V tunggal pada Gambar 1.

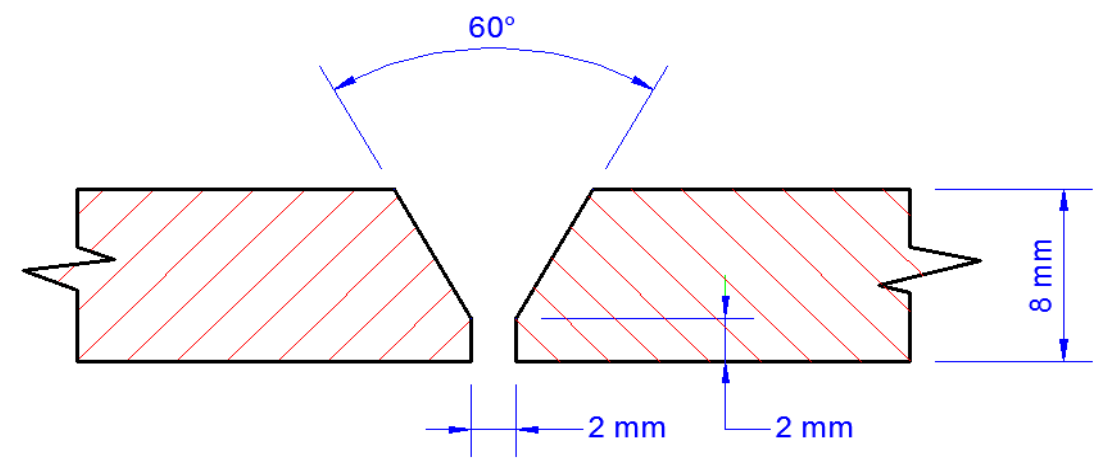

Gambar 1. Desain Kampuh V Tunggal

Pemilihan kampuh V tunggal karena dapat memberikan hasil kekuatan UTS maksimum dibandingkan dengan desain sambungan las lain [13]. Sambungan kampuh V tunggal dapat menahan stress dengan lebih baik daripada jenis sambungan lain [14]. Selain dapat memberikan hasil kekuatan UTS maksimum desain kampuh V tunggal juga dapat menahan stress dengan lebih baik dibandingkan jenis sambungan lain.

\subsection{Pengelasan}

Pengelasan dilakukan menggunakan mesin las Lorch $X$ 350. Dalam penelitian ini perlakuan suhu penyimpanan elektroda yang dilakukam yaitu $40^{\circ} \mathrm{C}, 80^{\circ} \mathrm{C}$, dan $120^{\circ} \mathrm{C}$ dengan waktu simpan 30 menit. Proses pengelasan sampel dilakukan dengan posisi 1G tanpa pemanasan awal (preheat) dan pemanasan paska las (post weld heat treatment), pengelasan sesuai parameter las seperti pada Tabel 3. Perlakuan pemanasan tersebut tidak dilakukan karena material SS400 memiliki nilai carbon equivalent (CE) <0,45. Nilai carbon equivalent (CE) jika kurang dari 0,45 tidak diperlukan pemanasan [15].

Tabel 3. Parameter Las

\begin{tabular}{|c|c|c|c|c|c|c|c|c|}
\hline \multirow[b]{2}{*}{ Weld Layers } & \multirow[b]{2}{*}{ Process } & \multicolumn{2}{|c|}{ Filler metals } & \multicolumn{2}{|l|}{ Current } & \multirow{2}{*}{$\begin{array}{l}\text { Volt } \\
(V)\end{array}$} & \multirow{2}{*}{$\begin{array}{c}\text { Travel speed } \\
\text { (mm/min) }\end{array}$} & \multirow{2}{*}{$\begin{array}{c}\text { Heat input } \\
(\mathrm{KJ} / \mathrm{mm})\end{array}$} \\
\hline & & Class & $\begin{array}{c}\text { Diameter } \\
(\mathrm{mm})\end{array}$ & Type of polarity & $\begin{array}{c}\text { Amp. } \\
\text { (A) }\end{array}$ & & & \\
\hline $1=$ Root pass & SMAW & E7016 & $\varnothing 2,6$ & DCSP & 80 & 21 & 109,54 & 0,92 \\
\hline $2=$ Hoot pass & SMAW & E7016 & $\varnothing 2,6$ & DCSP & 81 & 19 & 127,86 & 0,72 \\
\hline $3=$ Filler & SMAW & E7016 & $\varnothing 3,2$ & DCRP & 100 & 21 & 168,40 & 0,75 \\
\hline 4= Capping & SMAW & E7016 & $\varnothing 3,2$ & DCRP & 102 & 21 & 95,85 & 1,34 \\
\hline
\end{tabular}




\subsection{Pengujian Tekuk}

Pengujian tekuk dilakukan dengan tipe uji face bend dan root bend menggunakan alat uji tekuk kapasitas 10 ton. Spesimen dibuat dengan menggerinda permukaan dan akar las untuk menghasilkan permukaan yang rata dengan pelat. Ukuran spesimen uji tekuk yaitu 150 mm x 40 mm x 8 mm sesuai standar AWS D1.1, dapat dilihat pada Gambar 2.
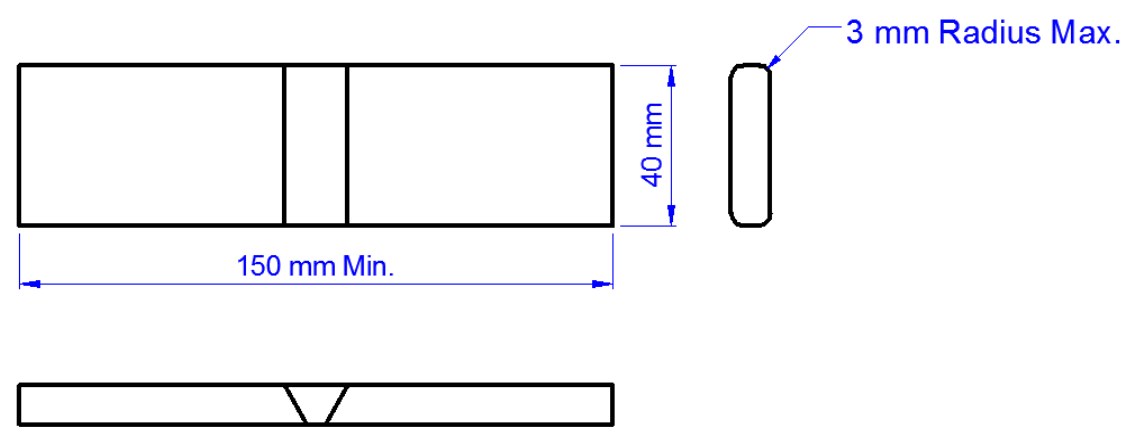

Gambar 2. Dimensi Spesimen Uji Tekuk

Pengambilan data uji tekuk dilakukan dengan mengukur diskontinuitas atau cacat yang terjadi pada permukaan lengkung spesimen. Kemudian untuk mengetahui hasil uji tekuk diterima atau tidak dilakukan berdasarkan kriteria penerimaan uji tekuk sesuai standar AWS D1.1 [16] yaitu permukaan lengkung tidak terdapat diskontinuitas melebihi; (1) $3 \mathrm{~mm}$ diukur ke segala arah di permukaan, (2) $10 \mathrm{~mm}$ jumlah dimensi terbesar dari semua diskontinuitas melebihi 1 mm, tetapi kurang dari atau sama dengan $3 \mathrm{~mm}$, dan (3) $6 \mathrm{~mm}$ retak sudut maksimum, kecuali ketika sudut itu retak hasil dari inklusi terak yang terlihat atau diskontinuitas jenis fusi lainnya, maka maksimal 3 mm berlaku.

\section{Hasil dan pembahasan}

Data pengujian face bend dan root bend dari hasil sambungan las menggunakan elektroda yang diberi perlakuan suhu penyimpanan dapat dilihat pada Tabel 4. Hasil data pengujian ini berdasarkan ukuran cacat yang terjadi pada permukaan lengkung spesimen setelah diuji tekuk. Spesimen hasil pengujian tekuk dengan menggunakan suhu penyimpanan $40^{\circ} \mathrm{C}, 80^{\circ} \mathrm{C}, 120^{\circ} \mathrm{C}$, dan tanpa perlakuan suhu ditunjukkan pada Gambar 3 .

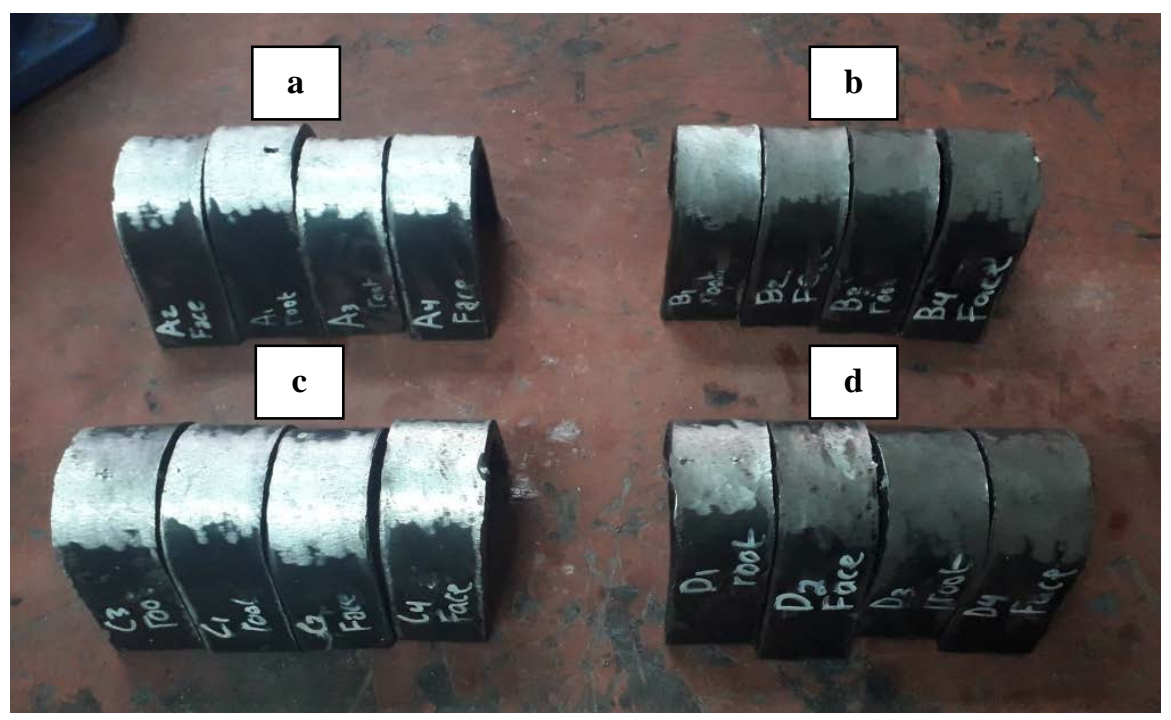

Gambar 3. Spesimen Uji Tekuk Setelah Diuji, a) Spesimen Kontrol, b) Suhu $40^{\circ}$ C, c) Suhu $80^{\circ} \mathrm{C}$, d) Suhu $120^{\circ} \mathrm{C}$ 
Tabel 4. Hasil Pengujian Tekuk

\begin{tabular}{|c|c|c|c|c|c|c|}
\hline \multirow{2}{*}{$\begin{array}{c}\text { Suhu } \\
\text { Penyimpanan }\end{array}$} & \multirow{2}{*}{$\begin{array}{c}\text { Kode } \\
\text { Spesimen } \\
\end{array}$} & \multirow{2}{*}{ Tipe Uji } & \multicolumn{3}{|c|}{ Keterangan } & \multirow{2}{*}{ Hasil } \\
\hline & & & Jenis Cacat & Ukuran (mm) & Lokasi & \\
\hline \multirow{9}{*}{ Spesimen Kontrol } & A1 & Root & $\begin{array}{l}\text { Incomplate } \\
\text { penetration }\end{array}$ & $7 \times 3$ & Weld metal & Tidak diterima \\
\hline & $\mathrm{A} 2$ & Face & - & - & - & Diterima \\
\hline & \multirow{2}{*}{ A3 } & \multirow{2}{*}{ Root } & Crack & 2 & Weld metal & \multirow{2}{*}{ Diterima } \\
\hline & & & Crack & 1,7 & $H A Z$ & \\
\hline & \multirow{5}{*}{ A4 } & \multirow{5}{*}{ Face } & Open crack & $1 \times 1$ & Weld metal & \multirow{5}{*}{ Diterima } \\
\hline & & & Crack & 1 & Weld metal & \\
\hline & & & Crack & 1,2 & HAZ & \\
\hline & & & Crack & 1 & Weld metal & \\
\hline & & & Crack & 1,9 & HAZ & \\
\hline \multirow{7}{*}{$40^{\circ} \mathrm{C}$} & B1 & Root & Open crack & $1,7 \times 0,6$ & Weld metal & Diterima \\
\hline & \multirow{2}{*}{ B2 } & \multirow{2}{*}{ Face } & \multirow{2}{*}{ Crack } & 1,6 & HAZ & \multirow{2}{*}{ Diterima } \\
\hline & & & & 1 & HAZ & \\
\hline & \multirow{3}{*}{ B3 } & \multirow{3}{*}{ Root } & Crack & 1,5 & Weld metal & \multirow{3}{*}{ Diterima } \\
\hline & & & Crack & 1,6 & Weld metal & \\
\hline & & & Crack & 1 & HAZ & \\
\hline & B4 & Face & Crack & 0,9 & $H A Z$ & Diterima \\
\hline \multirow{6}{*}{$80^{\circ} \mathrm{C}$} & $\mathrm{C} 1$ & Root & Open crack & $1,8 \times 1$ & Weld metal & Diterima \\
\hline & $\mathrm{C} 2$ & Face & - & - & - & Diterima \\
\hline & \multirow{3}{*}{ C3 } & \multirow{3}{*}{ Root } & Open crack & $2,3 \times 0,8$ & Weld metal & \multirow{3}{*}{ Tidak diterima } \\
\hline & & & Open crack & $2,4 \times 0,42$ & Weld metal & \\
\hline & & & Crack & 5,6 & Weld metal & \\
\hline & $\mathrm{C} 4$ & Face & Crack & 2 & Weld metal & Diterima \\
\hline \multirow{7}{*}{$120^{\circ} \mathrm{C}$} & \multirow{4}{*}{ D1 } & \multirow{4}{*}{ Root } & Open crack & $2 \times 0,76$ & Weld metal & \multirow{4}{*}{ Tidak diterima } \\
\hline & & & Open crack & $5,5 \times 0,4$ & Weld metal & \\
\hline & & & Open crack & $2 \times 2$ & Weld metal & \\
\hline & & & Crack & 1,22 & Weld metal & \\
\hline & $\mathrm{D} 2$ & Face & - & - & - & Diterima \\
\hline & D3 & Root & Crack & 2 & HAZ & Diterima \\
\hline & D4 & Face & - & - & - & Diterima \\
\hline
\end{tabular}

Hasil pengujian tekuk face bend dan root bend menunjukkan bahwa yang dinyatakan diterima berdasarkan standar AWS D1.1 adalah hasil pengelasan menggunakan suhu penyimpanan $40^{\circ} \mathrm{C}$. Pada pengujian face bend baik menggunakan perlakuan suhu maupun tanpa perlakuan setelah diuji terdapat retak dengan masing-masing ukuran $<3$ mm dan jumlah retak $<10$ mm dapat dilihat pada Tabel 4, berdasarkan standar retak tersebut diterima dengan ukuran tidak melebihi kriteria penerimaan. Berbeda dengan hasil uji root bend retak yang terjadi lebih tinggi dibandingkan dengan pengujian face bend, namun pada suhu $40^{\circ} \mathrm{C}$ retak yang terjadi rendah dan diterima berdasarkan standar. Hasil ini menunjukkan bahwa semakin tinggi suhu penyimpanan dapat menghasilkan retak yang tinggi terutama pada uji root bend. Dari hasil pengujian ini ada perbedaan daya tahan retak sambungan las dari efek suhu penyimpanan melalui uji face bend dengan root bend, daya tahan retak pada uji face bend lebih baik dibandingkan dengan uji root bend. 
Data hasil penerimaan (accepted) yang dihasilkan melalui pengujian face bend menunjukkan hasil yang bersesuaian dengan penelitian Wibowo [9] yang menyatakan bahwa hasil pengujian face bend baik tanpa maupun menggunakan pemanasan elektroda diterima dengan hasil retak dibawah standar yang diizinkan.

\section{Kesimpulan}

Hasil pengujian yang telah dilakukan menunjukkan bahwa suhu penyimpanan elektroda menghasilkan retak yang rendah pada uji face bend dibandingkan dengan pengujian root bend yang menghasilkan retak yang lebih tinggi (tidak diterima) dan hanya pemanasan pada suhu $40^{\circ} \mathrm{C}$ yang diterima berdasarkan standar AWS D1.1. Semakin tinggi suhu penyimpanan dapat menghasilkan retak yang tinggi terutama pada pengujian root bend.

\section{Daftar Pustaka}

[1] Bodude, MA., Momohjimoh, I., Studies on Effects of Welding Parameters on the Mechanical Properties of Welded Low-Carbon Steel. Journal of Minerals and Materials Characterization and Engineering. 2015 May; 3: 142-53.

[2] Selvam, R., Jacob, S., Experimental Investigation and Analysis of Smaw Processed Carbon Steel Pipes. International Journal of Mechanical and Production Engineering Research and Development. 2018 October; 8(5): 29-40.

[3] Jeffus, L., Welding and Metal Fabrication. United States of America: Cengage Learning; 2012.

[4] American Welding Society. Specification for Carbon Steel Electrodes for Shielded Metal Arc Welding. 2004: 32.

[5] Widharto, S., Welding Inspection. Jakarta: Mitra Wacana Media; 2013.

[6] ASME Section II Part C Specifications for Welding Rods, Electrodes, and Filler Metals. 2015: 67.

[7] Habibi, F., Respati, S.M.B., Syafa'at, I., Perlakuan Pemanasan awal Elektroda terhadap sifat Mekanik dan Fisik pada Daerah HAZ hasil pengelasan Baja Karbon ST 41. Prosiding Seminar Nasional Sains dan Teknologi ke-6. 2015; 1(1).

[8] Gumono, Hadi, S., Irawan, B., Perbandingan Suhu Penyimpanan Elektroda terhadap Kekerasan Baja Karbon. Info Teknik. 2018 Juli; 19(1).

[9] Wibowo, H., Surahmanto, F., Peningkatan Kekuatan Mekanis dan Ketahanan Retak Las pada Sambungan Las Busur Elektroda Terbungkus Melalui Pemanasan awal pada Elektroda. Prosiding Seminar Nasional Rekayasa Teknologi Industri dan Informasi ke-6. 2011.

[10] Daryanto, Teknik Las. Bandung: Alfabeta; 2014.

[11] Jeffus, L., Welding Principles and Application. $7^{\text {th }}$ edition. United States of America: Cengage Learning; 2012.

[12] Kobelco Welding Handbook. 2018.

[13] Dadi, A., Goyal, P.B., Patel, M.H., A Review Paper on Optimization of Shielded Metal Arc Welding Parameters for Welding of (Ms) Sa-516 Gr.70 Plate by Using Taguchi Approach. International Journal of Scientific Research in Science and Technology. 2018 April; 4(5): 1536-43.

[14] Nutalapati, S., Azad, D.D., Naidu, D.G.S., Effect of Welding Current on Welding Speed and Ultimate Tensile Strength (UTS) of Mild Steel. International Journal of Mechanical Engineering and Technology. 2016 SeptemberOctober; 7(5): 156-76.

[15] Odebiyi, O.S., Adedayo, S.M., Tunji, L.A., Onuorah, M.O., A Review of Weldability of Carbon Steel in ArcBased Welding Processes. Cogent Engineering. 2019 May; 6(1): 1-32.

[16] American Welding Society. Structural Welding Code-Steel. D1.1/D1.1M. 2015. 